\title{
Synthesis and Solvatochromic Behavior of Hexaphenylbenzenes and Indeno[1,2-b]fluorene Derivatives with Hydroxy Groups
}

\author{
Isao Yamaguchi", Kenta Tsuchie \\ Department of Chemistry, Interdisciplinary Graduate School of Faculty of Science and Engineering, \\ Shimane University, Matsue, Japan \\ Email: "iyamaguchi@riko.shimane-u.ac.jp
}

Received July 3, 2012; revised August 14, 2012; accepted August 26, 2012

\begin{abstract}
Hexakis(4-methoxyphenyl)benzene (HPB-OMe(1)) and hexakis(2,6-dimethyl-4-methoxyphenyl)benzene (HPB-OMe(2)) were synthesized via organometallic complex catalysis. The treatment of $\mathrm{HPB}-\mathrm{OMe}(1)$ with $\mathrm{FeCl}_{3}$ caused cyclodehydrogenation at two positions to yield an oligophenylene with an indeno[1,2-b]fluorene structure (IF-OMe). Deprotection of the methoxy groups of these compounds was conducted by treatment with $\mathrm{BBr}_{3}$. Deprotonation of the $\mathrm{OH}$ groups of HPB-OH(1), HPB-OH(2), and IF-OH through treatment with NaH caused a bathochromic shift in the absorption and photoluminescence (PL) peaks. The bathochromic shift of the deprotonated species increased with the donor number (DN) of the solvents. These observations can be explained as the consequence of intramolecular charge transfer (ICT) from the ONa groups to the inner benzene rings.
\end{abstract}

Keywords: Hexaphenylbenzene; Indeno[1,2-b]fluorene; Donor Number; Photoluminescence; Solvatochromism

\section{Introduction}

Oligo( $p$-phenylene)s (OPs) are an important class of $\pi$ conjugated oligomer [1-18]. We have recently reported on oligo( $p$-phenylene) compounds with an $\mathrm{OH}$ group located at either one end or at both ends, namely, $\operatorname{OPP}(n)$ -OH (where $n$ is the number of benzene rings) and HO$\operatorname{ArPh}(n)-\mathrm{OH}$ species $(\mathrm{Ar}=9,9$-dihexylfluorene -2,7-diyl and 2,5-dioctyloxybenzene-1,4-diyl), respectively [19, 20]. These $\mathrm{OPP}(n)-\mathrm{OH}$ and $\mathrm{HO}-\mathrm{ArPh}(n)-\mathrm{OH}$ compounds exhibited significant solvatochromism where deprotonation of the $\mathrm{OH}$ groups, when treated with $\mathrm{NaH}$, caused a bathochromic shift of $\lambda$ max that increased with the DN of the solvent. The solvatochromism exhibited by $\mathrm{OPP}(n)-\mathrm{ONa}$ and $\mathrm{NaO}-\mathrm{ArPh}(n)-\mathrm{ONa}$ was attributed to an ICT from the sodium phenoxy group(s) to the adjacent rings $[19,20]$. The degree of bathochromic shift in the deprotonated species increased with an increase in the chain length that corresponds to the expansion of the $\pi$-conjugation system. However, ICT behavior in branched oligophenylenes containing $\mathrm{OH}$ groups remains unclear.

Hexaphenylbenzenes (HPBs) are an important class of aromatic compounds in the field of materials science, acting as precursors for graphite-like, dendritic, or photo-

${ }^{*}$ Corresponding author. conductive polycyclic aromatic hydrocarbons [21,22]. HPBs also serve as guest-inclusion organic crystals directed to organic zeolites $[23,24]$. In this study, the optical properties of HPB-OH compounds were investigated before and after deprotonation of the $\mathrm{OH}$ groups. The $\pi$-conjugated system of the HPBs is comparatively small because of the presence of steric hindrance between the phenyl groups. We herein therefore also studied an OP which has its $\mathrm{OH}$ groups substituted with a planar indeno[1,2-b] fluorene structure (IF-OH), synthesized by the cyclodehydrogenation of HPB-OH, and subsequently investigated its solvatochromic behavior. IFs have attracted considerable attention because they can be useful materials for electroluminescence and photovoltaic devices $[25,26]$. These applications are based on the fact that IFs have a more extended coplanar, fused structure, which thus enables extended $\pi$-conjugation and improves their carrier mobilities compared to simple fluorene derivatives. The large carrier mobility in IFs is suited to the development of new solvatochromic materials based on ICT. The investigation into the optical properties of HPB-OH and IF-OH will afford information pertinent to the development of new solvatochromic materials. It is noteworthy that IF-OH is expected to be a useful starting material for the synthesis of new IFs through reactions using the $\mathrm{OH}$ groups. To the best of our knowledge, this 
is the first example of IFs with reactive groups.

We herein report on the synthesis of HPBs and IF with $\mathrm{OH}$ groups and their optical properties before and after the deprotonation of the $\mathrm{OH}$ groups.

\section{Experimental}

\subsection{General}

Solvents were dried, distilled, and stored under nitrogen. Reagents were purchased and used without further purification. Reactions were carried out with standard Schlenk techniques under nitrogen.

IR and NMR spectra were recorded on a JASCO FT/IR-660 PLUS spectrophotometer and a JEOL AL-400 spectrometer, respectively. Elemental analysis was performed on a Yanagimoto MT-5 CHN corder. UV-Vis and PL spectra were obtained by a JASCO V-560 spectrometer and a JASCO FP-6200 spectrofluorometer, respectively. Quantum yields were calculated by using a diluted ethanol solution of 7-dimethylamino-4-methylcoumarin as the standard.

\subsection{Synthesis}

\subsubsection{Synthesis of 1}

4-Bromoanisole (1.4 g, $7.5 \mathrm{mmol})$, bis(tributylstannyl) acetylene $(2.4 \mathrm{~g}, 3.9 \mathrm{mmol})$, and $\mathrm{Pd}\left(\mathrm{PPh}_{3}\right)_{4}(0.50 \mathrm{~g}, 0.43$ mmol) were dissolved in $20 \mathrm{ml}$ of dry toluene under $\mathrm{N}_{2}$. After the reaction solution was refluxed for $48 \mathrm{~h}$, the solvent was removed under vacuum. The resulting solid was purified by column chromatography (eluent $=\mathrm{CHCl}_{3}$ ) and recrystallized from chloroform. The yellow crystals were collected by filtration, washed with cold methanol, and dried under vacuum to give 1 as a yellow solid $(0.38$ g, 43\%). ${ }^{1} \mathrm{H}$ NMR (400 MHz, $\mathrm{CDCl}_{3}$ ): $\delta 7.45$ (d, $J=8.8$ $\mathrm{Hz}, 4 \mathrm{H}), 7.26(\mathrm{~d}, J=8.8 \mathrm{~Hz}, 4 \mathrm{H}), 3.83(\mathrm{~s}, 6 \mathrm{H}) .{ }^{13} \mathrm{C} \mathrm{NMR}$ $\left(100 \mathrm{MHz} \mathrm{CDCl}_{3}\right): \delta 156.8,140.3,133.6,132.5,112.2$, 55.0. Anal Calcd for $\mathrm{C}_{16} \mathrm{H}_{14} \mathrm{O}_{2}: \mathrm{C}, 80.65 ; \mathrm{H}, 5.92$. Found: C, 80.88; H, 6.10.

\subsubsection{Synthesis of 2}

2 was synthesized by the reaction of 2,5-dimethyl-4bromoanisole with bis(tributylstannyl)acetylene analogously.

Data of 2: Yield $=53 \% .{ }^{1} \mathrm{H}$ NMR $\left(400 \mathrm{MHz} \mathrm{CDCl}_{3}\right)$ : $\delta 7.18(\mathrm{~s}, 4 \mathrm{H}), 3.72(\mathrm{~s}, 6 \mathrm{H}), 2.27(\mathrm{~s}, 12 \mathrm{H}) .{ }^{13} \mathrm{C}$ NMR $(100$ $\left.\mathrm{MHz}, \mathrm{CDCl}_{3}\right): \delta 157.2,132.0,131.1,118.8,88.2,59.8$, 16.0. Anal Calcd for $\mathrm{C}_{20} \mathrm{H}_{22} \mathrm{O}_{2}: \mathrm{C}, 81.60 ; \mathrm{H}, 7.53$. Found: C, 81.44; H, 7.36.

\subsubsection{Synthesis of HPB-OMe(1)}

Dicobalt octacarbonyl $(0.068 \mathrm{~g}, 0.20 \mathrm{mmol})$ and $1(0.38$ $\mathrm{g}, 1.6 \mathrm{mmol})$ were dissolved in $20 \mathrm{ml}$ of dry toluene under $\mathrm{N}_{2}$. After the reaction solution was refluxed for $24 \mathrm{~h}$, the solvent was removed under vacuum. The resulting solid was purified by silica gel column chromatography (eluent $=\mathrm{CHCl}_{3}$ ), washed with methanol, and dried under vacuum to give $\mathrm{HPB}-\mathrm{OMe}(1)$ as a light brown solid $(0.30 \mathrm{~g}, 79 \%) .{ }^{1} \mathrm{H}$ NMR (400 MHz, $\left.\mathrm{CDCl}_{3}\right): \delta 6.67(\mathrm{~d}, J$ $=8.8 \mathrm{~Hz}, 12 \mathrm{H}), 6.42(\mathrm{~d}, J=8.8 \mathrm{~Hz}, 12 \mathrm{H}), 3.63(\mathrm{~s}, 18 \mathrm{H})$. ${ }^{13} \mathrm{C}$ NMR (100 MHz, DMSO- $\left.d_{6}\right): \delta 156.7,140.2,133.5$, 132.4, 112.1, 54.9. IR ( $\left.\mathrm{KBr}, \mathrm{cm}^{-1}\right): 3008,2957,2835$, $1611,1577,1518,1464,1419,1397,1287,1244,1178$, 1109, 1033, 834, 804, 551. Anal Calcd for $\mathrm{C}_{48} \mathrm{H}_{42} \mathrm{O}_{6} \cdot 0.25 \mathrm{H}_{2} \mathrm{O}$ : C, C, 80.14; H, 5.96. Found: C, 80.09; H, 5.99. $\mathrm{Mp}=378^{\circ} \mathrm{C}$.

\subsubsection{Synthesis of HPB-OMe(2)}

HPB-OMe(2) was synthesized using a procedure similar to that used for HPB-OMe(1) the analogous method.

Data of HPB-OMe(2): Yield $=65 \% .{ }^{1} \mathrm{H}$ NMR (400 $\left.\mathrm{MHz}, \mathrm{CDCl}_{3}\right): \delta 6.41(\mathrm{~s}, 12 \mathrm{H}), 3.50(\mathrm{~s}, 18 \mathrm{H}), 1.93$ (s, $36 \mathrm{H}) .{ }^{13} \mathrm{C}$ NMR $\left(100 \mathrm{MHz}, \mathrm{DMSO}-d_{6}\right): \delta 154.1,139.6$, $136.5,132.2,127.8,59.5,15.6 . \mathrm{IR}\left(\mathrm{KBr}, \mathrm{cm}^{-1}\right): 2935$, 1487, 1219, 1126, 1016, 867, 644. Anal Calcd for $\mathrm{C}_{60} \mathrm{H}_{66} \mathrm{O}_{6} \cdot 0.5 \mathrm{H}_{2} \mathrm{O}: \mathrm{C}, 80.77 ; \mathrm{H}, 7.57$. Found: $\mathrm{C}, 80.74 ; \mathrm{H}$, 7.14. $\mathrm{Mp}=254^{\circ} \mathrm{C}-255^{\circ} \mathrm{C}$.

\subsubsection{Synthesis of HPB-OH(1)}

After a dichloromethane solution $(5 \mathrm{ml})$ of $\mathrm{BBr}_{3}(0.34 \mathrm{ml}$, $3.6 \mathrm{mmol})$ was added dropwise to a dichloromethane solution (20 ml) of HPB-OMe(1) (0.096 g, $0.13 \mathrm{mmol})$, the reaction solution was stirred at $20^{\circ} \mathrm{C}$ for $30 \mathrm{~h}$ and quenched with water. The resulting precipitate was collected by filtration and dried under vacuum to give HPB-OH(1) as a pink solid $(0.047 \mathrm{~g}, 55 \%) .{ }^{1} \mathrm{H}$ NMR $\left(400 \mathrm{MHz}, \mathrm{CDCl}_{3}\right): \delta 8.83(\mathrm{~s}, 6 \mathrm{H}), 6.53(\mathrm{~d}, J=8.0 \mathrm{~Hz}$, $12 \mathrm{H}), 6.22(\mathrm{~d}, J=8.0 \mathrm{~Hz}, 12 \mathrm{H}) .{ }^{13} \mathrm{C}$ NMR $(125 \mathrm{MHz}$, $\left.\mathrm{CD}_{3} \mathrm{OD}\right): \delta 155.4,141.8,134.3,133.7,114.5$. IR $(\mathrm{KBr}$, $\left.\mathrm{cm}^{-1}\right): 3531,3340,3033,1612,1518,1436,1401,1261$, 1236, 1173, 1101, 1015, 826, 548. Anal Calcd for $\mathrm{C}_{42} \mathrm{H}_{30} \mathrm{O}_{6} \cdot 0.5 \mathrm{H}_{2} \mathrm{O}: \mathrm{C}, 78.86 ; \mathrm{H}, 4.88$. Found: $\mathrm{C}, 78.79 ; \mathrm{H}$, 4.72. $\mathrm{Mp}>400^{\circ} \mathrm{C}$.

\subsubsection{Synthesis of HPB-OH(2)}

$\mathrm{HPB}-\mathrm{OH}(2)$ was synthesized using a procedure similar to that used for HPB-OH(1) the analogous method.

Data of HPB-OH(2): Yield =91\%. ${ }^{1} \mathrm{H}$ NMR (400 MHz, DMSO- $\left.d_{6}\right): \delta 7.55(\mathrm{~s}, 6 \mathrm{H}), 6.42(\mathrm{~s}, 12 \mathrm{H}), 1.83(\mathrm{~s}, 36 \mathrm{H})$. ${ }^{13} \mathrm{C}$ NMR $\left(100 \mathrm{MHz}, \mathrm{DMSO}-d_{6}\right): \delta 150.0,140.4,132.8$, 131.7, 122.1, 16.9. IR ( $\left.\mathrm{KBr}, \mathrm{cm}^{-1}\right)$ : 3576, 3036, 2967, 2917, 2861, 1604, 1490, 1420, 1396, 1310, 1190, 1127, 1022, 943, 868, 730. Anal Calcd for $\mathrm{C}_{54} \mathrm{H}_{54} \mathrm{O}_{6} \cdot 0.2 \mathrm{H}_{2} \mathrm{O}: \mathrm{C}$, 80.81 ; H, 6.83. Found: C, 80.63; H, 6.97. $\mathrm{Mp}>400^{\circ} \mathrm{C}$.

\subsubsection{Synthesis of IF-OMe}

After a dichloromethane solution $(300 \mathrm{ml})$ of HPB$\mathrm{OMe}(1)$ (82 mg, $0.12 \mathrm{mmol})\left(\mathrm{N}_{2}\right.$ bubbled before use) 
was added to dry nitromethane solution $\left(7 \mathrm{ml} ; \mathrm{N}_{2}\right.$ bubbled before use $)$ of $\mathrm{FeCl}_{3}(0.37 \mathrm{~g}, 2.3 \mathrm{mmol})$ at $0^{\circ} \mathrm{C}$, the reaction solution was stirred at $20^{\circ} \mathrm{C}$ for $1.5 \mathrm{~h}$. The reaction solution was added to water $(50 \mathrm{ml})$, extracted with dichloromethane, and dried over magnesium sulfate. After the solvent was removed under vacuum, the resulting solid was washed with methanol, collected filtration, and dried under vacuum to give IF-OMe as a light brown solid (57 mg, 72\%). ${ }^{1} \mathrm{H} \mathrm{NMR}\left(400 \mathrm{MHz}, \mathrm{CDCl}_{3}\right): \delta 7.18$ $(\mathrm{d}, J=8.4 \mathrm{~Hz}, 4 \mathrm{H}), 6.90(\mathrm{~d}, J=8.0 \mathrm{~Hz}, 4 \mathrm{H}), 6.51-6.57$ $(\mathrm{m}, 8 \mathrm{H}), 6.23(\mathrm{~d}, J=8.8 \mathrm{~Hz}, 2 \mathrm{H}), 6.14(\mathrm{~d}, J=9.6 \mathrm{~Hz}$, $4 \mathrm{H}), 3.88(\mathrm{~s}, 6 \mathrm{H}), 3.68(\mathrm{~s}, 6 \mathrm{H}) .{ }^{13} \mathrm{C} \mathrm{NMR}(125 \mathrm{MHz}$, $\left.\mathrm{CDCl}_{3}\right): \delta 185.9,159.9,159.5,149.7,144.2,142.3,138.9$, $134.7,134.1,130.8,129.0,128.3,124.4,114.9,113.6$, 109.2, 56.6, 55.5, 55.4. IR (KBr, $\left.\mathrm{cm}^{-1}\right): 2936,2836,1661$, 1604, 1521, 1496, 1457, 1436, 1247, 1174, 1024, 861, 833. Anal Calcd for $\mathrm{C}_{46} \mathrm{H}_{34} \mathrm{O}_{6} \cdot \mathrm{H}_{2} \mathrm{O}$ : C, 78.84; H, 5.18. Found: $\mathrm{C}, 78.55 ; \mathrm{H}, 5.07 . \mathrm{Mp}=399^{\circ} \mathrm{C}-403^{\circ} \mathrm{C}$.

\subsubsection{Synthesis of IF-OH}

After a dichloromethane solution $(2 \mathrm{ml})$ of $\mathrm{BBr}_{3}(0.21 \mathrm{ml}$, $2.2 \mathrm{mmol})$ was added to a dichloromethane solution (13 $\mathrm{ml})$ of IF-OMe $(0.057 \mathrm{~g}, 0.083 \mathrm{mmol})$, the reaction solution was stirred at $20^{\circ} \mathrm{C}$ for $30 \mathrm{~h}$ and quenched with water. The resulting precipitate was collected by filtration and dried under vacuum to give IF-OH as a green solid $(0.030 \mathrm{~g}, 58 \%) .{ }^{1} \mathrm{H}$ NMR (400 MHz, DMSO- $\left.d_{6}\right): \delta 9.61$ (s, 2H), 9.56 (s, 2H), 7.05 (d, $J=8.0 \mathrm{~Hz}, 4 \mathrm{H}), 6.66(\mathrm{~d}, J$
$=8.0 \mathrm{~Hz}, 4 \mathrm{H}), 6.45(\mathrm{~d}, J=8.4 \mathrm{~Hz}, 2 \mathrm{H}), 6.35(\mathrm{~s}, 2 \mathrm{H})$, $6.08(\mathrm{~d}, J=8.4 \mathrm{~Hz}, 2 \mathrm{H}), 6.00(\mathrm{~d}, J=9.6 \mathrm{~Hz}, 4 \mathrm{H}) .{ }^{13} \mathrm{C}$ NMR $\left(125 \mathrm{MHz}\right.$, DMSO- $\left.d_{6}\right): \delta 184.2,157.0,156.9$, $149.7,143.8,141.9,137.9,133.9,130.3,127.8,127.7$, $126.5,123.4,115.2,114.3,110.3,55.8 . \quad \operatorname{IR}\left(\mathrm{KBr}, \mathrm{cm}^{-1}\right)$ : 3301, 1652, 1608, 1524, 1434, 1364, 1236, 1173, 1106, 868, 839. Anal Calcd for $\mathrm{C}_{42} \mathrm{H}_{26} \mathrm{O}_{6} \cdot \mathrm{H}_{2} \mathrm{O}: \mathrm{C}, 78.25 ; \mathrm{H}$, 4.38. Found: $\mathrm{C}, 78.11 ; \mathrm{H}, 4.65 . \mathrm{Mp}>400^{\circ} \mathrm{C}$.

\section{Results and Discussion}

\subsection{Synthesis}

Indeno[1,2-b]fluorene derivatives were synthesized by the methods shown in Scheme 1. The 1:2 Stille coupling reacon of bis(tributylstannyl)acetylene with 4-bromoanisole and 4-bromo-2,5-dimethylanisole yielded bis(4-methoxyenyl)acetylene (1) and bis(3,5-dimethyl-4-ethoxyphenyl) cetylene (2), respectively. The $\mathrm{Co}_{2}(\mathrm{CO})_{8}$-catalyzed cyclotrimerization of 1 and 2 yielded HPB-OMe(1) and HPB$\mathrm{OMe}(2)$ in $79 \%$ and $65 \%$ yields, respectively. The treatment of $\mathrm{HPB}-\mathrm{OMe}(1)$ with $\mathrm{FeCl}_{3}$ caused oxidative cyclodehydrogenation to yield IF-OMe. It has been rerted that the treatment of HPBs with $\mathrm{FeCl}_{3}$ can cause cyclodehydrogenation to yield compounds with an inno[1,2-b]fluorene structure [27]. The deprotection of the OMe groups of $\mathrm{HPB}-\mathrm{OMe}(1)$, HPB-OMe(2), and IF-Me with $\mathrm{BBr}_{3}$ resulted in the production of $\mathrm{HPB}-\mathrm{OH}(1), \mathrm{HPB}-\mathrm{H}(2)$, and IF-OH, respectively.

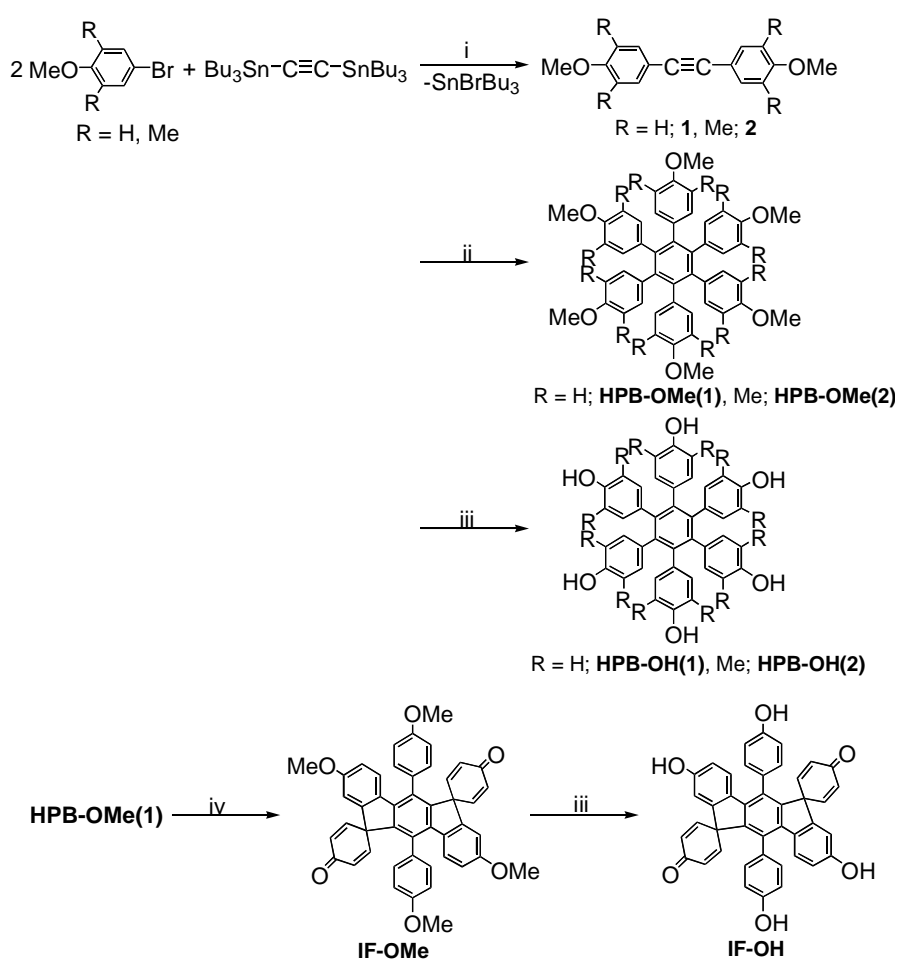

Scheme 1. Synthesis of HPBs and oligophenylenes with an indeno[1,2-b]fluorene structure. i) $\left.\mathrm{Pd}_{(\mathrm{PPh}}\right)_{4}$, reflux, toluene, $48 \mathrm{~h}$; ii) $\mathrm{Co}_{2}(\mathrm{CO})_{8}$, toluene, reflux, $24 \mathrm{~h}$; iii) $\mathrm{BBr}_{3}, \mathrm{CH}_{2} \mathrm{Cl}_{2}, 20{ }^{\circ} \mathrm{C}, 30 \mathrm{~h}$; iv) $\mathrm{FeCl}_{3}, \mathrm{CH}_{3} \mathrm{NO}_{2}, \mathrm{CH}_{2} \mathrm{Cl}_{2}, 1.5 \mathrm{~h}$. 
The structures of the newly synthesized compounds were determined by ${ }^{1} \mathrm{H}$ and ${ }^{13} \mathrm{C}$ NMR spectroscopy and elemental analysis. The solubilities of the obtained compounds are summarized in Table 1. HPB-OMe(1) and $\mathrm{HPB}-\mathrm{OMe}(2)$ were soluble in polar organic solvents such as 1,4-dioxane, tetrahydrofuran (THF), $N, N$-imethylformamide (DMF) and dimethyl sulfoxide (DMSO) as well as in less polar organic solvents such as chloroform and dichloromethane. However, HPB-OH(1) and HPB-OH(2) were soluble in DMF and DMSO but insoluble in dichloromethane and chloroform because of the presence of hydrophilic $\mathrm{OH}$ groups. IF-OMe was soluble in dichloromethane and 1,4-dioxane but insoluble in polar organic solvents such as DMF and DMSO, whereas IF-OH was soluble in the polar organic solvents because of the presence of the $\mathrm{OH}$ groups but insoluble in less polar organic solvents.

\subsection{IR and NMR Spectra}

Figure 1 shows the IR spectra of HPB-OMe(1), HPB$\mathrm{H}(1)$, HPB-OH(2), and IF-OH The main features of the IR spectra of HPB-OMe(1) and HPB-OMe(2) were identical, with absorption bands resulting from $\mathrm{C}-\mathrm{O}$ stretching, the presence of a phenyl ring, and out-of- lane C-H bending vibrations of $p$-phenylene observed at approximately $1244 \mathrm{~cm}^{-1}, 1517 \mathrm{~cm}^{-1}$, and $804 \mathrm{~cm}^{-1}$, respectively. Similarly, the main features of the IR spectra of HPB-OH(1) and HPB-OH(2) were identical, except for the absorption resulting from the $\mathrm{O}-\mathrm{H}$ stretching, with the absorption bands resulting from $\mathrm{C}-\mathrm{O}$ stretching, the presence of a phenyl ring, and out-of-plane $\mathrm{C}-\mathrm{H}$ bending vibrations of $p$-phenylene observed at approximately $1261 \mathrm{~cm}^{-1}, 1518 \mathrm{~cm}^{-1}$, and $826 \mathrm{~cm}^{-1}$, respectively. The IR spectrum of HPB-OH(1) exhibited a strong sharp absorption due to the hydrogen bonding free $\mathrm{OH}$ group at $3576 \mathrm{~cm}^{-1}$ and a broad absorption due to the hydrogen bonding $\mathrm{OH}$ group at around $3340 \mathrm{~cm}^{-1}$. In contrast, while the IR spectrum of HPB-OH(2) exhibited a strong sharp absorption due to the hydrogen bonding free $\mathrm{OH}$ group at $3576 \mathrm{~cm}^{-1}$, no absorption was observed for the hydrogen bonding $\mathrm{OH}$ group. The inhibition of intermolecular hydrogen bonding in $\mathrm{HPB}-\mathrm{OH}(2)$ is attributed to

Table 1. Solubility of the obtained compounds.

\begin{tabular}{cccccc}
\hline & $\begin{array}{c}\text { Dichloro- } \\
\text { methane }\end{array}$ & 1,4-Dioxane & THF & DMF & DMSO \\
\hline HPB-OMe(1) & ++ & + & ++ & -- & -- \\
HPB-OMe(2) & ++ & ++ & ++ & -- & -- \\
HPB-OH(1) & -- & -- & + & ++ & + \\
HPB-OH(2) & -- & -- & ++ & ++ & ++ \\
IF-OMe & ++ & ++ & -- & -- & -- \\
IF-OH & -- & -- & ++ & ++ & ++ \\
\hline
\end{tabular}

++: Soluble; +: Partly soluble; --: Insoluble.

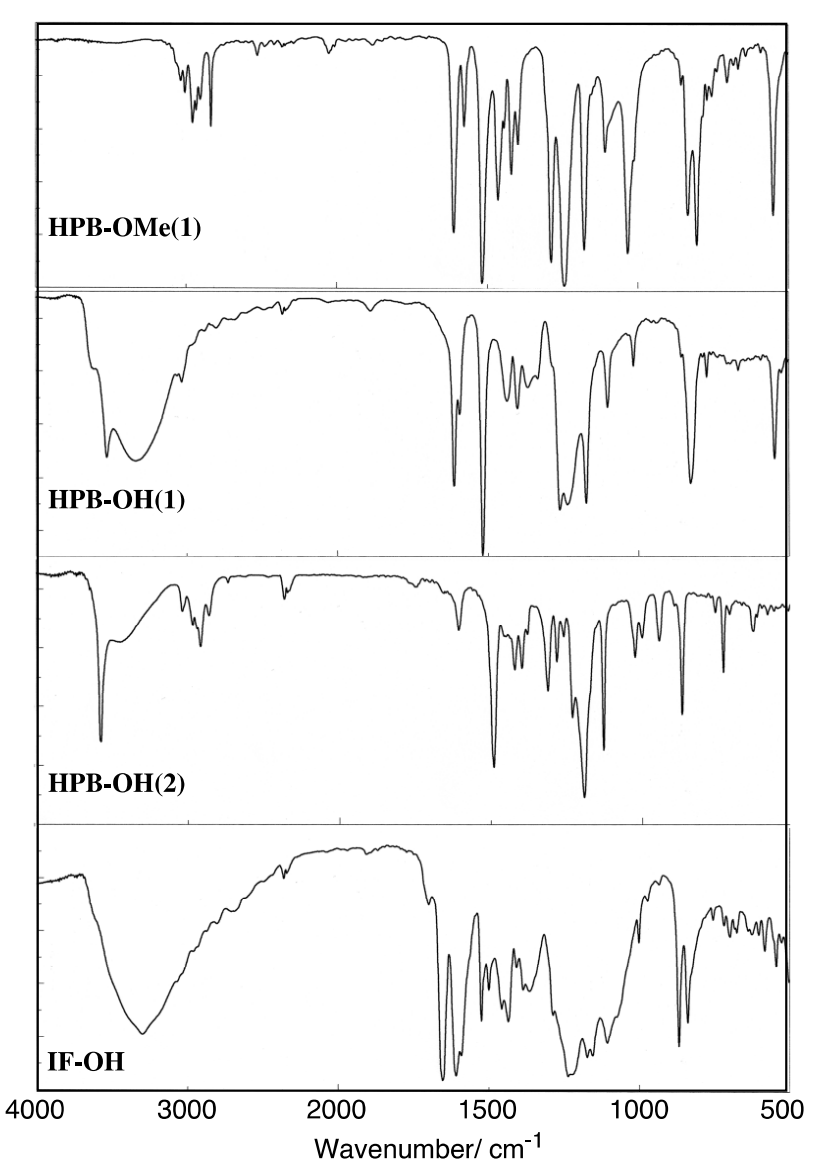

Figure 1. IR spectra of HPB-OMe(1), HPB-OH(1), HPBOH(2), and IF-OH.

the presence of the methyl groups at the 2- and 6-positions in HPB-OH(2). The IR spectrum of IF-OMe exhibited absorption bands corresponding to $\mathrm{C}=\mathrm{O}$ and $\mathrm{C}-\mathrm{O}$ stretching vibrations and out-of-plane $\mathrm{C}-\mathrm{H}$ bending vibrations of $p$-phenylene, observed at $1661 \mathrm{~cm}^{-1}, 1246$ $\mathrm{cm}^{-1}$, and $833 \mathrm{~cm}^{-1}$, respectively. IF-OH exhibited absorption peaks corresponding to hydrogen bonding $\mathrm{O}-\mathrm{H}$ stretching vibrations in the range $2500-3300 \mathrm{~cm}^{-1}$, and peaks corresponding to $\mathrm{C}=\mathrm{O}$ and $\mathrm{C}-\mathrm{O}$ stretching vibrations and out-of-plane $\mathrm{C}-\mathrm{H}$ bending vibrations of $p$ phenylene at $1652 \mathrm{~cm}^{-1}, 1236 \mathrm{~cm}^{-1}$, and $868 \mathrm{~cm}^{-1}$, respectively. The fact that the band corresponding to the $\mathrm{C}=\mathrm{O}$ stretching vibrations of $\mathrm{IF}-\mathrm{OH}$ was observed at a shorter wavenumber than that for IF-OMe is attributed to the intermolecular hydrogen bonding via the $\mathrm{OH}$ group.

The ${ }^{1} \mathrm{H}$ NMR spectra of HPB-OMe(1) and HPB- Me(2) exhibited a peak corresponding to the methoxy H-atoms at $\delta 3.63$ and 3.50, respectively, and that of IF-OMe(1) exhibited two peaks corresponding to the methoxy $\mathrm{H}$-atoms at $\delta 3.68$ and 3.88. These peaks disappeared in the ${ }^{1} \mathrm{H}$ NMR spectra of the corresponding deprotected species, thus suggesting that the deprotection reaction proceeded to completion. The peaks corresponding to the 
phenyl H-atoms of HPB-OMe(1) and HPB-OMe(2) were observed at higher magnetic field positions than those of 1 and 2. These observations may be due to the presence of the ring current effect in HPB-OMe(1) and $\mathrm{HPB}-\mathrm{OMe}(2)$. The peaks corresponding to the $\mathrm{OH}$ groups of HPB-OH(1) and HPB-OH(2) were observed at $\delta 8.83$ and 7.56, respectively, whereas those of IF-OH were observed at $\delta 9.56$ and 9.61. The fact that the peak corresponding to the $\mathrm{OH}$ groups of HPB-OH(2) was observed at a higher magnetic field position than that of HPB-OH(1) is because of the presence of the electron-donating methyl groups adjacent to the $\mathrm{OH}$ groups in $\mathrm{HPB}-\mathrm{OH}(2)$.

Deprotonation of the OH groups of HPB-OH(1), HPB$\mathrm{OH}(2)$, and IF-OH was carried out through treatment with an excess amount of NaH in DMSO- $d_{6}$. The result is that the signal corresponding to the $\mathrm{OH}$ group disappeared from the ${ }^{1} \mathrm{H}$ NMR spectra for solutions of HBC$\mathrm{OH}, \mathrm{HPB}-\mathrm{OH}(1)$, HPB-OH(2), and IF-OH(1) in the presence of $\mathrm{NaH}$, indicating that the deprotonation proceeded quantitatively.

\subsection{UV-Vis Absorption and Solvatochromism}

Figure 2 shows the UV-Vis spectra of $\mathrm{HPB}-\mathrm{OMe}(1)$, HPB-OMe(2), HPB-OH(1), HPB-OH(2), IF-OMe, IF$\mathrm{OH}$, and their deprotonated species in organic solvents. The optical data of these compounds are summarized in Tables 2-4. The THF solutions of HPB-OH(1) and HPB-OH(2) each exhibited three absorption peaks. It has been reported that $m$-terphenyl can be regarded as a combination of two molecules of biphenyl of the $\mathrm{C}_{1}$ group [28]. The observation of three absorption peaks in HPB-OH(1) probably derives from the assumption that it can be regarded as a combination of three molecules of dihydroxy-o-, $m$-, and $p$-terphenyl. $o-, m$-, and $p$-terphenyls exhibit an absorption peak at $260 \mathrm{~nm}, 240 \mathrm{~nm}$, and $290 \mathrm{~nm}$, respectively. These wavelengths are consistent with those observed for the THF solution of HPB-OH(1). The absorption peaks of HPB-OH(2) are observed at shorter wavelengths than those of HPB$\mathrm{OH}(1)$. This observation is attributed to the larger bond twisting between the 2,6-dimethyl-4-methoxyphenyl ring and the central benzene ring in HPB-OH(1) compared with that between the 4-methoxyphenyl ring and the central benzene ring in HPB-OH(2). As shown in Figure 2iii, the UV-Vis spectra of IF-OMe and IF-OH can be divided into two clearly distinguishable parts. These two regions appear to be separate states of electronic transition, shown in Figure 3. The absorption peak at $238 \mathrm{~nm}$ is probably a result of the electronic transition directed along the $\mathrm{a}$ and $\mathrm{b}$ axes, while those in the range of 310 $344 \mathrm{~nm}$ are likely due to the electronic transition directed along the c, d, and e axes, respectively, as shown in Fig- ure 4. The models of the electronic transition axes were proposed in the case of branched oligophenylenes. In $\mathrm{CH}_{2} \mathrm{Cl}_{2}$ and 1,4-dioxane, the $\lambda$ max values of IF-OMe were longer than those of HPB-OMe(1) because of the presence of the planar indeno[1,2-b]fluorene structure in IF-OMe.
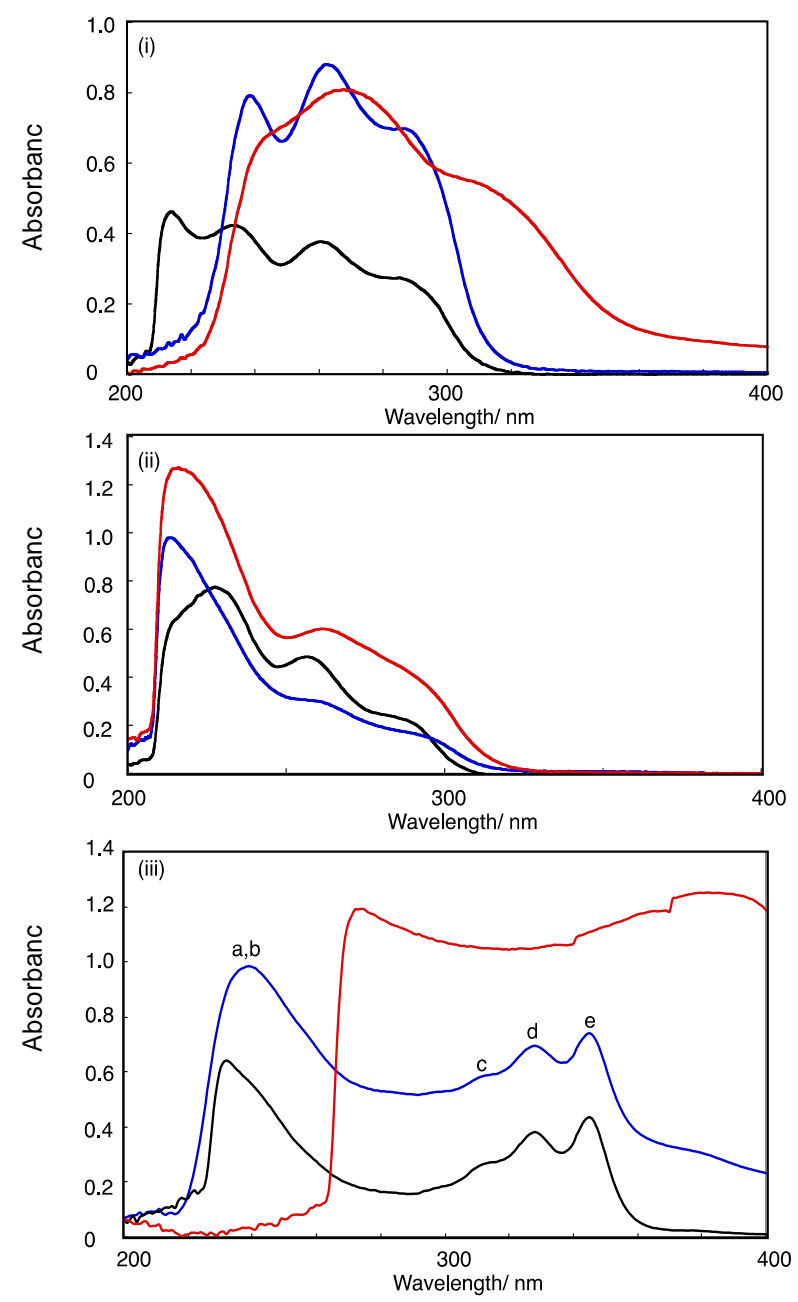

Figure 2. UV-Vis spectra of HPB-OMe(1) (i; black curve), HPB-OMe(2) (ii; black curve), HPB-OH(1) (i; blue curve), HPB-OH(2) (ii; blue curve), and their deprotonated species (i, ii, iii; red curves) in THF, IF-OMe in dichloromethane (iii; black curve), and IF-OH (iii; blue curve) and IF-ONa (iii; red curve) in DMSO.

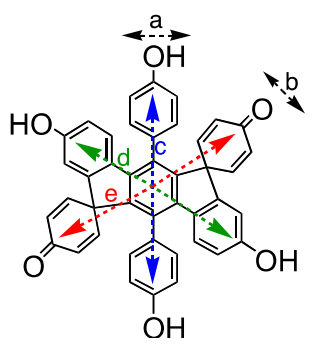

Figure 3. Electronic transition directions in IF-OH. 
Table 2. Optical data of HPB-OMe(1), HPB-OH(1), and HPB-ONa(1).

\begin{tabular}{|c|c|c|c|c|c|c|c|}
\hline & \multirow[b]{2}{*}{$\mathrm{DN}^{\mathrm{a}}$} & \multicolumn{2}{|c|}{ HPB-OMe(1) } & \multicolumn{2}{|c|}{ HPB-OH(1) } & \multicolumn{2}{|c|}{$\mathrm{HPB}-\mathrm{ONa}(1)$} \\
\hline & & absorption, $\mathrm{nm}^{\mathrm{b}}$ & emission, $\mathrm{nm}^{\mathrm{c}}$ & absorption, $\mathrm{nm}^{\mathrm{b}}$ & emission, $\mathrm{nm}^{\mathrm{c}}$ & absorption, $\mathrm{nm}^{\mathrm{b}}$ & emission, $\mathrm{nm}^{\mathrm{c}}$ \\
\hline dichloromethane & 0 & $\begin{array}{c}232(4.75), 260(4.59) \\
283(4.45)^{\mathrm{d}}\end{array}$ & $359(267)$ & $\mathrm{e}$ & $\mathrm{e}$ & $\mathrm{e}$ & $\mathrm{e}$ \\
\hline 1,4-dioxane & 14.8 & 261,283 & $356(284)$ & e & e & $\mathrm{e}$ & $\mathrm{e}$ \\
\hline THF & 20 & $\begin{array}{l}214(4.66), 234(4.63) \\
261(4.58), 285(4.44)^{d}\end{array}$ & $352(268)$ & $238,262,288$ & 353 & $267(5.21), 308(5.04)^{\mathrm{d}}$ & $404(286)$ \\
\hline DMF & 26.6 & $271,282^{\mathrm{d}}$ & $358(282)$ & $\begin{array}{l}270(4.48) \\
287(4.41)^{d}\end{array}$ & $360(283)$ & $308(4.71)$ & $412(284)$ \\
\hline DMSO & 29.8 & $265,282^{d}$ & $355(282)$ & 283 & $354(290)$ & 304 & $440(290)$ \\
\hline
\end{tabular}

${ }^{\mathrm{a}} \mathrm{DN}=$ Donor number; ${ }^{\mathrm{b}}$ Loge values are shown in the parenthesis; ${ }^{\mathrm{c}}$ Excitation wavelengths are shown in the parenthesis; ${ }^{\mathrm{d}}$ Shoulder peak; ${ }^{\mathrm{e}}$ Not measured due to low solubility.

Table 3. Optical data of HPB-OMe(2), HPB-OH(2), and HPB-ONa(2).

\begin{tabular}{|c|c|c|c|c|c|c|c|}
\hline & \multirow[b]{2}{*}{$\mathrm{DN}^{\mathrm{a}}$} & \multicolumn{2}{|c|}{ HPB-OMe(2) } & \multicolumn{2}{|c|}{ HPB-OH(2) } & \multicolumn{2}{|c|}{ HPB-ONa(2) } \\
\hline & & absorption, $\mathrm{nm}^{\mathrm{b}}$ & emission, $\mathrm{nm}^{\mathrm{c}}$ & absorption, $\mathrm{nm}^{\mathrm{b}}$ & emission, $\mathrm{nm}^{\mathrm{c}}$ & absorption, $\mathrm{nm}^{\mathrm{b}}$ & emission, $\mathrm{nm}^{\mathrm{c}}$ \\
\hline dichloromethane & 0 & $\begin{array}{c}232(4.82), 254(4.61), \\
285(4.23)^{\mathrm{d}}\end{array}$ & $354(267)$ & e & 367 (269) & $\mathrm{e}$ & $\mathrm{e}$ \\
\hline 1,4-dioxane & 14.8 & 256 (4.90), 285 (4.59) & $354(285)$ & $\begin{array}{c}240(4.60), 255(4.52), \\
288(4.20)^{\mathrm{d}}\end{array}$ & $371(269)$ & $244(4.76), 269(4.64)^{\mathrm{d}}$ & 371 (269) \\
\hline THF & 20 & $\begin{array}{c}227(4.89), 257(4.69), \\
286(4.36)^{\mathrm{d}}\end{array}$ & $350(269)$ & $261(4.78)$ & $370(269)$ & $271(4.89)$ & $426(271)$ \\
\hline DMF & 26.6 & $269(4.90), 284(4.77)^{\mathrm{d}}$ & $350(284)$ & $269(4.79), 292(4.56)^{\mathrm{d}}$ & $375(282)$ & $268(4.86), 300(4.78)$ & $479(285)$ \\
\hline DMSO & 29.8 & $264(4.32), 284(4.07)^{\mathrm{d}}$ & $362(284$ & $265(4.35), 285(4.18)^{\mathrm{d}}$ & $380(280)$ & $285(4.96)$ & $520(419)$ \\
\hline
\end{tabular}

${ }^{\mathrm{a}} \mathrm{DN}=$ Donor number; ${ }^{\mathrm{b}}$ Loge values are shown in the parenthesis; ${ }^{\mathrm{c}}$ Excitation wavelengths are shown in the parenthesis; ${ }^{\mathrm{d}}$ Shoulder peak; ${ }^{\mathrm{e}}$ Not measured due to low solubility.

Table 4. Optical data of IF-OMe, IF-OH, and IF-ONa.

\begin{tabular}{|c|c|c|c|c|c|c|c|}
\hline & \multirow[b]{2}{*}{$\mathrm{DN}^{\mathrm{a}}$} & \multicolumn{2}{|c|}{ IF-OMe(1) } & \multicolumn{2}{|c|}{$\mathrm{IF}-\mathrm{OH}(1)$} & \multicolumn{2}{|c|}{$\mathrm{IF}-\mathrm{ONa}(1)$} \\
\hline & & absorption, $\mathrm{nm}^{\mathrm{b}}$ & emission, $\mathrm{nm}^{\mathrm{c}}$ & absorption, $\mathrm{nm}^{\mathrm{b}}$ & emission, $\mathrm{nm}^{\mathrm{c}}$ & absorption, $\mathrm{nm}^{\mathrm{b}}$ & emission, $\mathrm{nm}^{\mathrm{c}}$ \\
\hline dichloromethane & 0 & $\begin{array}{l}232(4.81), 312(4.42), \\
328(4.58), 345(4.64)\end{array}$ & 453 (349), 493 & d & d & d & d \\
\hline 1,4-dioxane & 14.8 & $\begin{array}{l}245(4.50), 312(4.30) \\
328(4.44), 346(4.51)\end{array}$ & $455(350), 473,504$ & d & d & d & d \\
\hline THF & 20 & d & d & $\begin{array}{l}238(4.29), 310(4.06), \\
327(4.14), 344(4.17)\end{array}$ & 447 (339) & d & $443(340)$ \\
\hline DMF & 26.6 & d & d & $\begin{array}{l}268(3.92), 312(3.89) \\
329(4.01), 346(4.06)\end{array}$ & $449(341), 474$ & $382(4.40)$ & $502(412)$ \\
\hline DMSO & 29.8 & d & d & $\begin{array}{l}265(4.16), 315(4.18), \\
330(4.30), 347(4.35)\end{array}$ & $\begin{array}{c}452(364) \\
476,507\end{array}$ & $406(4.58)$ & $504(389)$ \\
\hline
\end{tabular}

${ }^{a} \mathrm{DN}=$ Donor number; ${ }^{\mathrm{b}}$ Loge values are shown in the parenthesis; ${ }^{\mathrm{c}}$ Excitation wavelengths are shown in the parenthesis; ${ }^{\mathrm{d}}$ Not measured due to low solubility. 

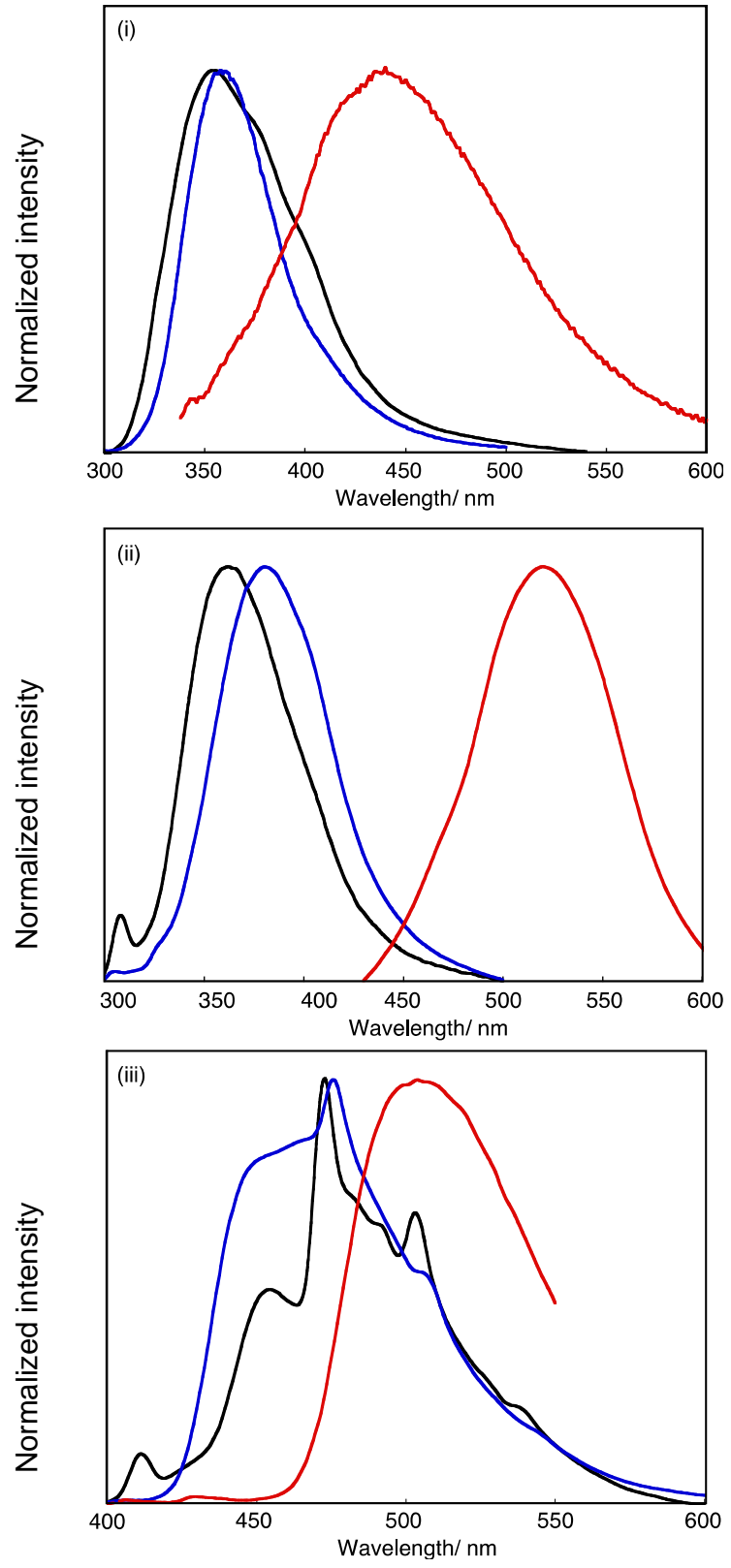

Figure 4. PL spectra of HPB-OMe(1) (i; black curve), HPB-OMe(2) (ii; black curve), HPB-OH(1) (i; blue curve), HPB-OH(2) (ii; blue curve), IF-OH (iii; blue curve), and their deprotonated species (i, ii, iii; red curve) in DMSO and IF-OMe (iii; black curve) in 1,4-dioxane.

The treatment of the DMSO solutions of $\mathrm{HBC}-\mathrm{OH}$, HPB-OH(1), HPB-OH(2), and IF-OH(1) with $\mathrm{NaH}$ causes a bathochromic shift in absorption bands by approximately $20-60 \mathrm{~nm}$. The formation of HBC-ONa, $\mathrm{HPB}-\mathrm{ONa}(1)$, HPB-ONa(2), and IF-ONa(1) was mainly responsible for the shift of $\lambda$ max towards a longer wavelength. To prove that these observations were due to the deprotonation of the $\mathrm{OH}$ groups after treatment with $\mathrm{NaH}$, we confirmed that there was no change in the absorption spectra of HBC-OMe, HPB-OMe(1), HPB-OMe(2), and IF-OMe(1) upon the addition of NaH. The absorption peaks at $238 \mathrm{~nm}, 262 \mathrm{~nm}$, and $288 \mathrm{~nm}$ in the UV-Vis spectrum of HPB-OH(1) correspond to the $\pi-\pi^{*}$ transition of the $m$-, $o$-, and $p$-terphenyl moieties in this compound, respectively. These peaks shifted to longer wavelengths after treatment with $\mathrm{NaH}$, by $5 \mathrm{~nm}, 5 \mathrm{~nm}$, and 20 $\mathrm{nm}$, respectively. The degree of bathochromic shift in the peak that corresponds to the electric transition along the $p$-terphenyl moiety was the largest of the three described. This result suggests that ICT from the ONa group to the inner benzene rings was preferred through the $p$-terphenyl moiety. No significant bathochromic shift was observed in HPB-ONa(2). This is because of the bond twisting between the 2,6-dimethyl -4-methoxyphenyl and central benzene rings. The UV-Vis spectrum of IF-ONa was somewhat ambiguous because it was partly soluble in organic solvents. However, bathochromic shifts were observed in the case of IF-ONa.

The bathochromic shift attributable to deprotonation is dependent on the DN of the solvent used. As summarized in Tables 2-4, absorptions for HPB-OH(1), HPB-OH(2), and their deprotonated species shifted to longer wavelengths as the DN of the solvent was increased. In contrast to the small bathochromic shift for HPB-OH(1) and HPB-OH(2), with an increase in the DN of the solvent, the $\lambda$ max values of $\mathrm{HPB}-\mathrm{ONa}(1)$ and $\mathrm{HPB}-\mathrm{ONa}(2)$ were larger than those of HPB-OH(1) and HPB-OH(2). For example, the $\lambda$ max value of $\mathrm{HPB}-\mathrm{ONa}(2)$ varies from $244 \mathrm{~nm}$ in 1,4-dioxane ( $\mathrm{DN}=14.8)$ to $285 \mathrm{~nm}$ in DMSO $(\mathrm{DN}=29.8)$, through to a value of $271 \mathrm{~nm}$ in THF $(\mathrm{DN}=$ 20.0). Similarly, that of HPB-ONa(1) varies from $267 \mathrm{~nm}$ in THF $(\mathrm{DN}=20.0)$ to $304 \mathrm{~nm}$ in DMSO $(\mathrm{DN}=29.8)$. The large $\Delta \lambda$ value can be attributed to the fact that solvents with a high DN effectively solvate with $\mathrm{Na}^{+}$to stabilize the deprotonated species in the solutions. Similar solvatochromic behavior was observed in the cases of $\operatorname{OPP}(n)-\mathrm{OH}(n=4$ and 5$)$ and $\mathrm{OPP}(n)-\mathrm{ONa}(n=4$ and 5), as reported earlier [29]. The fact that the $\Delta \lambda$ values for HPB-ONa(2) were smaller than those for HPB-ONa(1) corresponds to the reduced length of $\pi$-conjugation in HPB-ONa(2) that arises from the bond twisting between 2,6-dimethyl-4-methoxyphenyl and the central benzene rings.

\subsection{Photoluminescence}

The compounds obtained in this study and their deprotonated species are photoluminescent in solution. The photoluminescence (PL) data are summarized in Tables 2-4. Figure 4 shows the PL spectra of HPB-OMe(1), HPB-OMe(2), HPB-OH(1), HPB-OH(2), IF-OMe, IF-OH, and their deprotonated species in organic solvents. The PL peak positions for HPB-OH(1), HPB-OH(2), and 


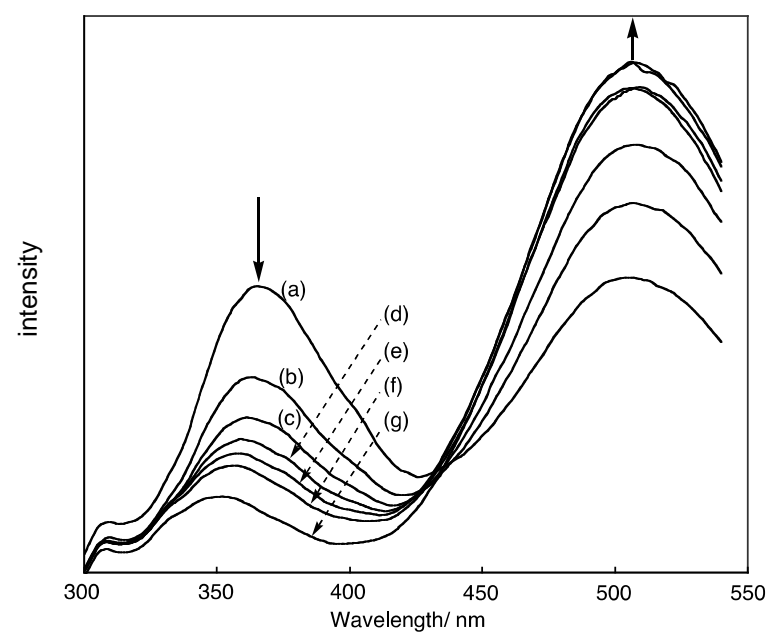

Figure 5. Changes of PL spectra of methanol solution of HPB(1)-OH $\left(5 \times 10^{-5} \mathrm{M}\right)$ in the presence of various amounts of NaOH. (a): $0 \mathrm{M}$; (b): $3 \times 10^{-2} \mathrm{M}$; (c): $4 \times 10^{-2} \mathrm{M}$; (d): $5 \times$ $10^{-2} \mathrm{M} ;(\mathrm{e}): 6 \times 10^{-2} \mathrm{M}$; (f): $7 \times 10^{-2} \mathrm{M} ;(\mathrm{g}): 8 \times 10^{-2} \mathrm{M}$.

IF-OH shifted to longer wavelengths after deprotonation with $\mathrm{NaH}$. This shift is comparable to the bathochromic shift observed in the UV-Vis spectra of these compounds. The emission peak positions for HPB-OH(1), HPB$\mathrm{OH}(2), \mathrm{IF}-\mathrm{OH}$, and their deprotonated species depended on the DN of the solvent. As summarized in Tables 2-4, by varying solvents such as $\mathrm{CH}_{2} \mathrm{Cl}_{2}$ and 1,4-dioxane, which have small DN values, with those such as DMF and DMSO, which have large DN values, it is observed that the emission peak positions for HPB-OH(1) and HPB-OH(2) shift by only $3-13 \mathrm{~nm}$. However, a significantly large shift in the emission peaks for $\mathrm{HPB}-\mathrm{ONa}(1)$, HPB-ONa(2), and IF-ONa(1) occurred as the DN of the solvent was increased. These observations are consistent with the result that, with an increase in the DN of the solvent, $\lambda$ max of HPB-ONa(1), HPB-ONa(2), and IF$\mathrm{ONa}(1)$ in solution shifts to a longer wavelength than that of HPB-OH(1), HPB-OH(2), and IF-OH(1). The remarkable solvatochromic shift of the PL peak position of HPB-ONa(1) and HPB-ONa(2) may be due to the shift in charge from the phenolate group to the adjacent rings. In addition to the effect of charge shift, a large amount of stabilization energy produced by the solvation of HPB$\mathrm{ONa}(1)$ and HPB-ONa(2) may contribute to the solvatochromic red shift as the DN of the solvent is increased. There was no change in the PL spectra of HPB-OMe(1), $\mathrm{HPB}-\mathrm{OMe}(2)$, and IF-OMe(1) upon the addition of $\mathrm{NaH}$, which suggests that the solvatochromism in HPB$\mathrm{ONa}(1), \mathrm{HPB}-\mathrm{ONa}(2)$, and IF-ONa(1) can be attributed to the deprotonation of the $\mathrm{OH}$ group after treatment with $\mathrm{NaH}$.

Figure 5 shows the PL spectra of the methanol solutions of HPB(1)-OH containing different amounts of $\mathrm{NaOH}$. It is observed that the peak at $371 \mathrm{~nm}$ decreases and a new emission peak at $475 \mathrm{~nm}$ appears as the concentration of the base is increased. This result confirms the fact that the emission peaks at $371 \mathrm{~nm}$ and $475 \mathrm{~nm}$ originate from $\mathrm{HPB}(1)-\mathrm{OH}$ and $\mathrm{HPB}(1)-\mathrm{ONa}$, respectively.

The quantum yields of the PLs of the DMF solutions of HPB-ONa(1) and HPB-ONa(2) were $2 \%, 7 \%$, respectively, while those of HPB-OH(1) and HPB-OH(2) were $24 \%$ and $8 \%$, respectively. The fact that the quantum yields of the PLs of HPB-ONa(1) and HPB-ONa(2) are lower than those of HPB-OH(1) and HPB-OH(2) is attributed to the intramolecular charge shift (ICT) in $\mathrm{HPB}-\mathrm{ONa}(1)$ and $\mathrm{HPB}-\mathrm{ONa}(2)$. It has been reported that the ICT in $\pi$-conjugated molecules reduces their PL emission efficiencies [8].

\section{Conslusion}

HPBs with hydroxyl groups (HPB-OH species) and their derivatives with an indeno[1,2-b]fluorene structure were obtained by using reactions with transition metal complexes. The treatment of these compounds with a base produced corresponding deprotonated species, whose absorption and PL peak positions in solution shifted towards longer wavelengths with an increase in the DN of the solvent. The optical properties of the HPB-OH compounds were significantly affected by bond twisting between the hydroxyphenyl group and the central benzene ring. The introduction of a planar indeno[1,2-b]fluorene structure to the HPB-OH enhanced its solvatochromic behavior. The results obtained in this study will be useful in providing information for the development of new solvatochromic materials.

\section{Acknowledgements}

This work was performed under the Cooperative Research Program of "Network Joint Research Center for Materials and Devices" (No. 2011193).

\section{REFERENCES}

[1] M. Era, T. Tsutsui and S. Saito, "Polarized Electroluminescence from Oriented $p$-Wexiphenyl Vacuum-deposited Film," Applied Physics Letters, Vol. 67, No. 17, 1995, pp. 2436-2438. doi:10.1063/1.114599

[2] J. M. Kauffman, P. T. Litak, J. A. Novinski, C. J. Kelly, A. Ghiorghis and Y. Qin, "Electronic Absorption and Emission Spectral Data and Fluorescence Quantum Yields of Bridged $p$-Oligophenylenes, Bi- to Deciphenyls, and Related Furans and Carbazoles," Journal Of Fluorescence, Vol. 5, No. 3, 1995, pp. 295-305. doi:10.1007/BF00723901

[3] J. M. Tour, "Conjugated Macromolecules of Precise Length and Cssonstitution. Organic Synthesis for the Construction of Nanoarchitectures," Chemical Reviews, 
Vol. 96, No. 1, 1996, pp. 537-554. doi: $10.1021 / \mathrm{cr} 9500287$

[4] F. Meghdadi, G. Leising, W. Fisher and F. Stelzer, "Multicolour Electroluminescence Diodes Using Oligophenylene and Oligophenylenevinylene Multilayers," Synthetic Metals, Vol. 76, No. 1-3, 1996, p. 113. doi:10.1016/0379-6779(95)03430-R

[5] D. J. Grundlach, Y. Y. Lin, T. N. Jackson and D. G. Schlom, "Oligophenyl-Based Organic Thin Film Transistors," Applied Physics Letters, Vol. 71, No. 26, 1997 , pp. 3853-3855. doi:10.1063/1.120524

[6] Y. Z. Wang, R. G. Sun, F. Meghdadi, G. Leising and A. J. Epstein, "Multicolor Multilayer Light-Emitting Devices Based on Pyridine-containing Conjugated Polymers and Para-Sexiphenyl Oligomer," Applied Physics Letters, Vol. 74, No. 24, 1999, pp. 3613-3615. doi: $10.1063 / 1.123198$

[7] R. E. Martin and F. Diederich, "Linear Monodisperse $\pi$-Conjugated Oligomers: Model Compounds for Polymers and More," Angewandte Chemie International Edition, Vol. 38, No. 10, 1999, pp. 1350-1377. doi:10.1002/(SICI)1521-3773(19990517)38:10

[8] V. Sidorov, T. Douglas, S. M. Dzekunov, D. Abdallah, B. Ghebremariam, P. D. Roepe and S. Matile, "Self-Assembled Single-Chain Oligo( $p$-Phenylene) Amphiphiles: Reversed Micelles, Vesicles and Gels," Chemical Communications, No. 15, 1999, pp. 1429-1430. doi:10.1039/A903041G

[9] B. Baumeister and S. Matile, "Programmed Assembly of Expanded Rigid-Rod $\beta$-Barrels by Supramolecular Preorganization," Chemical Communications, No. 11, 2000, pp. 913-914. doi:10.1039/B002113J

[10] B. Baumeister, N. Sakai, S. Matile, "Giant Artificial Ion Channels Formed by Self-Assembled, Cationic RigidRod $\beta$-Barrels," Angewandte Chemie International Edi- tion, Vo. 39, No. 11, 2000, pp. 1955-1958. doi:10.1002/1521-3773(20000602)39:11

[11] R. L. Carroll and C. B. Gorman, "The Genesis of Molecular Electronics," Angewandte Chemie International Edition, Vol. 41, No. 23, 2002, 4378-4400. doi: 10.1002/1521-3773(20021202)41:23

[12] O. Deeg, P. Kirsch, D. Pauluth and P. Bäuerle, "Combinatorial Parallel Synthesis and Automated Screening of a Novel Class of Liquid Crystalline Materials," Chemical Communications, No. 23, 2002, pp. 2762-2763. doi:10.1039/B207630F

[13] Z. N. Yu, H. L. Tu, X. H. Wan, Z. F. Chen and Q. F. Zhou, "Synthesis and Properties of Liquid Crystalline 4,4"-Dialkoxy-2"-Methyl-P-Terphenyls," Molecular Crystals and Liquid Crystals, Vol. 391, No. 1, 2002, pp. 41-55. doi:10.1080/15421400390193567

[14] Z.-H. Li, M.-S. Wong, Y. Tao and M. D'Iorio, "Synthesis and Functional Properties of Strongly Luminescent Diphenylamino End-Capped Oligophenylenes," Journal of Organic Chemistry, Vol. 69, No. 3, 2004, pp. 921-927. doi:10.1021/jo035147y

[15] K.-H. Ahn, G. Y. Ryu, S.-W. Youn and D.-M. Shin, “The Conjugation Effects on the Luminescence Properties of Oligophenylenes for the OLED," Materials Science and
Engineering: C, Vol. 24, No. 1-2, 2004, pp. 163-165. doi: 10.1016/j.msec.2003.09.010

[16] A. P. H. J. Schenning and E. W. Meijer, "Supramolecular Electronics; Nanowires from Self-Assembled $\pi$-Conjugated Systems," Chemical Communications, No. 26, 2005, pp. 3245-3258. doi: 10.1039/B501804H

[17] H. Yin, G.-I. Lee, K. A. Sedey, O. Kutzki, H. S. Park, B. P. Orner, J. T. Ernst, H.-G. Wang, S. M. Sebti and A. D. Hamilton, "Terphenyl-Based Bak BH3 $\alpha$-Helical Proteomimetics as Low-Molecular-Weight Antagonists of Bclx," Journal of American Chemical Society, Vol. 127, No. 29, 2005, pp. 10191-10196. doi:10.1021/ja050122x

[18] N. H. Sultana, S. M. Kelly, B. Mansoor and N. O’Neill, "Polycatenar Oligophenylene Liquid Crystals," Liquid Crystals, Vol. 34, No. 11, 2007, pp. 1307-1316. doi:10.1080/02678290701682357

[19] I. Yamaguchi, K. Goto and M. Sato, "Synthesis of Oligophenylenes Containing Hydroxyl Group and Their Solvatochromic Behavior," Tetrahedron, Vol. 65, No. 18, 2009, pp. 3645-3654. doi:10.1016/j.tet.2009.02.073

[20] I. Yamaguchi, K. Seo and Y. Kawashima, "Synthesis of Dihydroxyoligophenylenes Containing $\pi$-Deficient or $\pi$ Excess Hetero-Aromatic Rings and Their Solvatochromic Behavior," Tetrahedron, Vol. 34, No. 7, 2010, pp. 67256732. doi:10.1016/j.tet.2010.06.087

[21] A. J. Berresheim, M. Müller and K. Müllen, "Polyphenylene Nanostructures," Chemical Reviews, Vol. 99 No. 7, 1999, pp. 17471786. doi:10.1021/cr970073+

[22] V. Garg, "Design and Synthesis of Hexaphenylbenzene Based Artificial Photosynthetic Antenna-Reaction Centers," Umi Dissertation Publishing, Proquest, 2011.

[23] K. E. Maly, E. Gagnon, T. Maris and J. D. Wuest, "Engineering Hydrogen-Bonded Molecular Crystals Built from Derivatives of Hexaphenylbenzene and Related Compounds," Journal of American Chemical Society, Vol. 129, No. 14, 2007, pp. 4306-4322. doi:10.1021/ja067571x

[24] K. Kobayashi, T. Shirasaka, A. Sato, E. Horn and N. Furukawa, "Self-Assembly of a Radially Functionalized Hexagonal Molecule: Hexakis(4-hydroxyl-phenyl)benzene," Angewandte Chemie International Edition, Vol. 38, No. 23, 1999, pp. 3483-3486. doi:10.1002/(SICI)1521-3773(19991203)38:23

[25] Y. Xia, Z. He, J. Tong, B. Li, C. Wang, Y. Cao, H. Wu, H. Y. Woo and D. Fan, "Synthesis and Photovoltaic Properties of Alternating Conjugated Polymers Derived from Indeno[1,2- $b]$ fluorene and Bithiophene or Thieno[3,2b]thiophene-Cored Benzothiadiazole," Macromolecular Chemistry and Physics, Vol. 212, No. 11, 2011, pp. 1193 1201. doi:10.1002/macp.201000759

[26] E. Jeong, S. H. Kim, I. H. Jung, Y. Xia, K. Lee, H. Suh, H.-K. Shim and H. Y. Woo, "Synthesis and Characterization of Indeno[1,2-b]fluorene-based White Light-Emitting Copolymer," Journal of Polymer Science: Part A: Polymer Chemistry, Vol. 47, No. 14, 2009, pp. 3467-3479. doi: $10.1002 /$ pola. 23422

[27] S. H. Wadumethrige and R. Rathore, "A Facile Synthesis of Elusive Alkoxy-Substituted Hexa-peri-hexabenzocoronene," Organic Letters, Vol. 10, No. 22, 2008, pp. 5139-5142. doi: 10.1021/o18020429 
[28] N. I. Nijegorodov, W. S. Downey and M. B. Danailov, "Systematic Investigation of Absorption, Fluorescence and Laser Properties of Some $p$ - and $m$-Oligophenylenes," Spectrochimica Acta A, Vol. 56, No. 4, 2000, pp. 783-795. doi:10.1016/S1386-1425(99)00167-5
[29] X. Zhang, A. S. Shetty and S. A. Jenekhe, "Electroluminescence and Photophysical Properties of Polyquinolines," Macromolecules, Vol. 32, No. 22, 1999, pp. 7422 7429. doi:10.1021/ma990960+ 